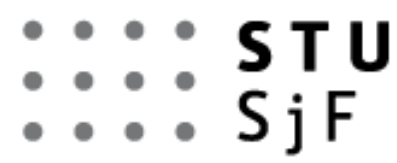

DE GRUYTER OPEN

\title{
INFLUENCE OF INDUCTION HARDENING ON WEAR RESISTANCE IN CASE OF ROLLING CONTACT
}

\author{
ŠOFER, Michal ${ }^{1}$, FAJKOŠ, Rostislav ${ }^{2}$, HALAMA, Radim ${ }^{3}$ \\ ${ }^{1}$ VSB-Technical University of Ostrava, Faculty of Mechanical Engineering, Department of Applied Mechanics, \\ 17.listopadu 15, Ostrava, 17. listopadu 15/2127, 70833 Ostrava-Poruba, Czech Republic; \\ email: michal.sofer@vsb.cz \\ ${ }^{2}$ VSB-Technical University of Ostrava, Faculty of Mechanical Engineering, Department of Applied Mechanics, \\ 17.listopadu 15, Ostrava, 17. listopadu 15/2127, 70833 Ostrava-Poruba, Czech Republic; \\ email: rostislav.fajkos@vsb.cz \\ ${ }^{3}$ VSB-Technical University of Ostrava, Faculty of Mechanical Engineering, Department of Applied Mechanics, \\ 17.listopadu 15, Ostrava, 17. listopadu 15/2127, 70833 Ostrava-Poruba, Czech Republic; \\ email: radim.halama@vsb.cz
}

\begin{abstract}
The main aim of the presented paper is to show how heat treatment, in our case the induction hardening, will affect the wear rates as well as the ratcheting evolution process beneath the contact surface in the field of line rolling contact. Used wear model is based on shear band cracking mechanism [1] and non-linear kinematic and isotropic hardening rule of Chaboche and Lemaitre. The entire numerical simulations have been realized in the $\mathrm{C \#}$ programming language. Results from numerical simulations are subsequently compared with experimental data.
\end{abstract}

KEYWORDS: Rolling Contact Fatigue, Wear, Ratcheting, R7T

\section{Introduction}

Interaction between rail and wheel still represents a very complex set of problems to be described. Hardening of surface and subsurface layers as well as crack propagation mechanism, which is influenced by many factors [2] (presence of lubricant in the contact, material hardness of surface and subsurface layers, etc.), play a significant role.

Ratcheting is, in case of dry rolling/sliding contact, the prevailing wear mechanism and governs the accumulation process of plastic shear deformation.

The crack growth can be described by a presence of two phases: initiation of a crack and its further propagation. The crack initiation is started when the critical value of the plastic shear strain is reached, while the crack propagation phase is driven by the actual value of the shear stress [3].

In most cases, nucleated cracks grow in the parallel direction to the contact surface and cause material delamination - flanking phenomena (Fig. 1). According to Merwin and Johnson [4], the orthogonal shear strain $\gamma_{\mathrm{xz}}$ is the only component responsible for accumulation of plastic shear strain beneath contact surface.

Nowadays, the semi-analytical approaches are powerful tools used for wear and ratcheting prediction. One of them is the approach proposed by A. Mazzu [1], who has utilized a simplified non-linear kinematic hardening model based on the Chaboche-Lemaitre plasticity model. The model is based on the assumption that the only stress component responsible for 
plastic flow is $\tau_{\mathrm{xz}}$ (Fig. 2). The proposed hypothesis is, however, not valid at shallow depths beneath the contact surface where $\sigma_{\mathrm{x}}$ stress component plays a major role in plastic shear accumulation (Fig. 2). One year later, Mazzu published a correction of his algorithm which was based on the influence of $\sigma_{\mathrm{x}}$ stress component on the shear strain accumulation process at shallow depths beneath the contact surface [5]. The proposed paper presents a numerical study of wear prediction of two sets of R7T steel grade, one of which was inductively hardened (Set 1). The elastic stress field, needed for numerical computations based on the semi-analytical approach [5], is originally obtained by the Boussinesq approximation. The numerical simulations also take into account the variation of traction coefficient obtained from realized experiments. Chaboche material parameters has been determined by use of an algorithm with random number generator. All procedures have been written in the C\# programming language.

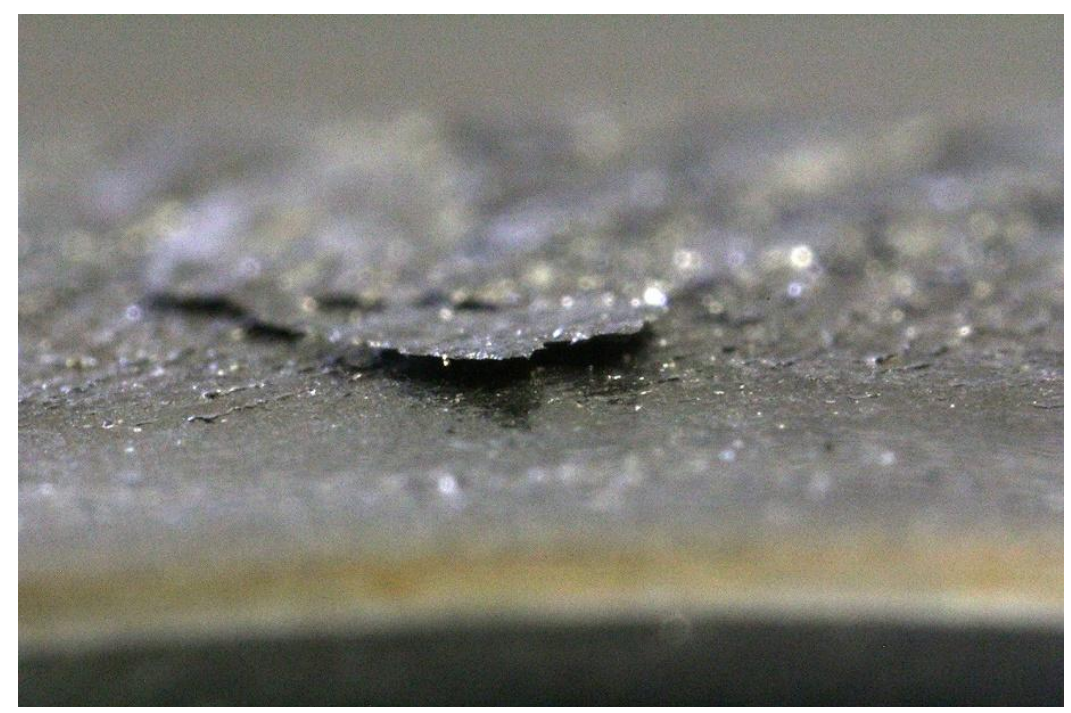

Fig. 1. Flanking phenomena.

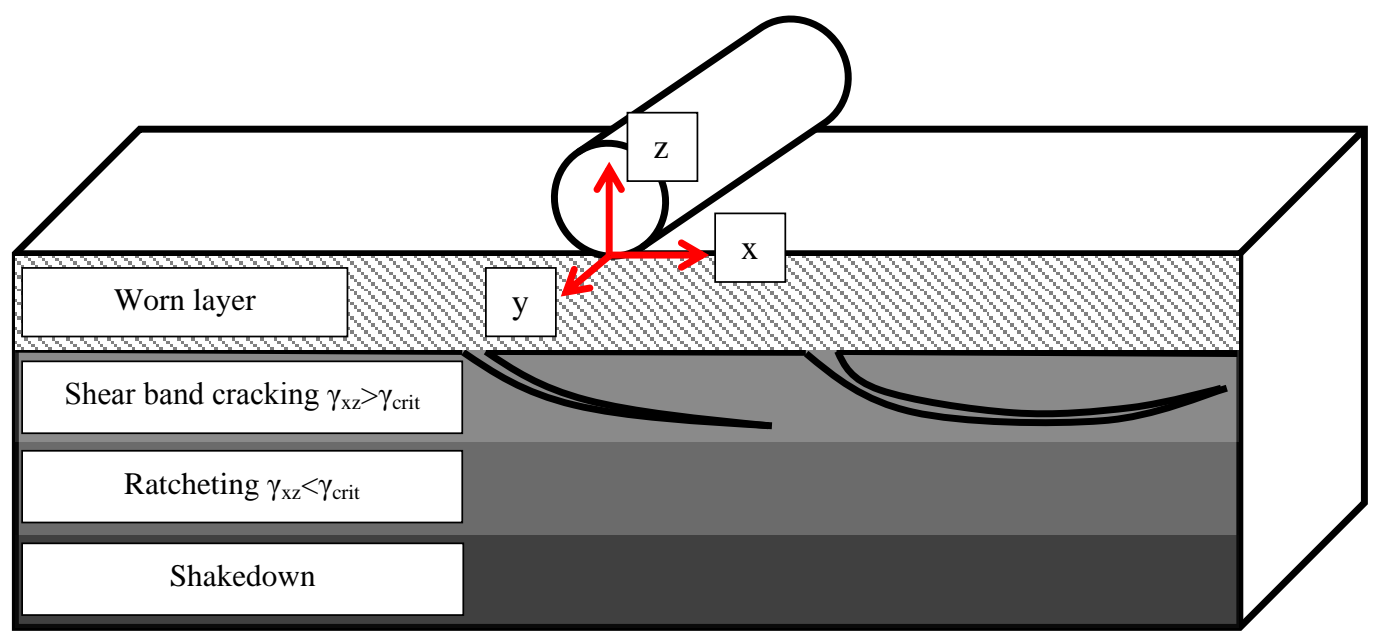

Fig. 2. Shear band cracking mechanism. 


\section{Rolling contact fatigue tests}

All rolling contact wear tests were performed in the Rolling Contact Fatigue Laboratory at the Department of Mechanics of Materials of the VŠB-Technical University of Ostrava on TUORS testing device [2]. Results of wear tests of specimen from the R7T steel without additional induction hardening are described in detail in [6]. For both sets of specimen (inductively hardened and non-inductively hardened), the diameter of the wheel disc was $82.45 \mathrm{~mm}$, whereas the diameter of the rail disc was $215.55 \mathrm{~mm}$. The rail specimen was made of steel class $\mathrm{C}$. The difference between the diameters of the specimen and the diameters of gears in the gearbox generated a creepage of $0.75 \%$. The Hertzian contact pressure was set at $1200 \mathrm{MPa}$. The torque was recorded during the entire testing of both sets of specimens. After selected number of cycles (10000, 20000 and 60000), the testing procedure was stopped and the weight and diameter loss as well as the roughness of the contact surface of the wheel specimen were evaluated. The following table summarizes the values of loss of radius for both sets calculated from weight loss after a particular number of cycles. Figure 4 shows the course of friction coefficient for both sets of specimen.

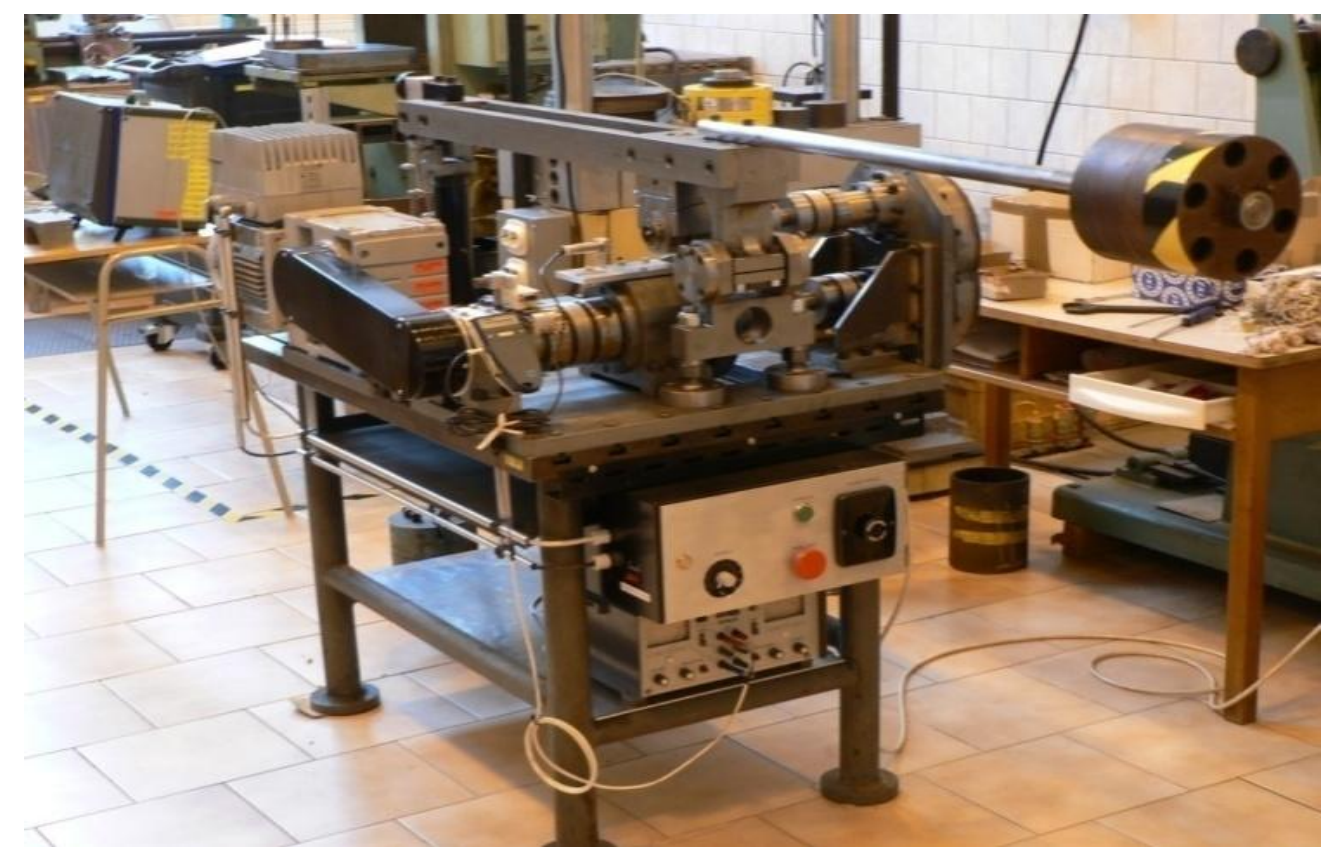

Fig. 3. TUORS testing machine.

Table 1 Loss of radii for two sets of R7T specimen.

\begin{tabular}{|c|c|c|c|}
\hline \multicolumn{2}{|c|}{ Set 1 - R7T (with ind. hardening ) } & \multicolumn{2}{c|}{ Set 2 - R7T (without ind. hardening ) } \\
\hline Number of cycles [-] & Loss of radius [mm] & Number of cycles [-] & Loss of radius [mm] \\
\hline 10000 & 0.0006 & 10000 & 0.0127 \\
\hline 20000 & 0.011 & 20000 & 0.0327 \\
\hline 60000 & 0.049 & 60000 & 0.1127 \\
\hline
\end{tabular}

After $6 \cdot 10^{4}$ cycles, the wheel specimen from set 1 was subjected to metallographic analysis focused on the evaluation of the critical value of plastic shear deformation $\left(\gamma_{\text {crit }}\right)$. It is worth mentioning that the value of critical plastic shear deformation for the specimen from the set 2 had been already evaluated and subsequently published in [6]. The evaluation procedure was realized according to the methodology described in [7]. Specimen from the set 1 (with 
induction hardening) exhibited the value of 3.41 [-], whereas the critical shear deformation for specimen from the set 2 (without induction hardening) reached the value of $9.81[-]$.

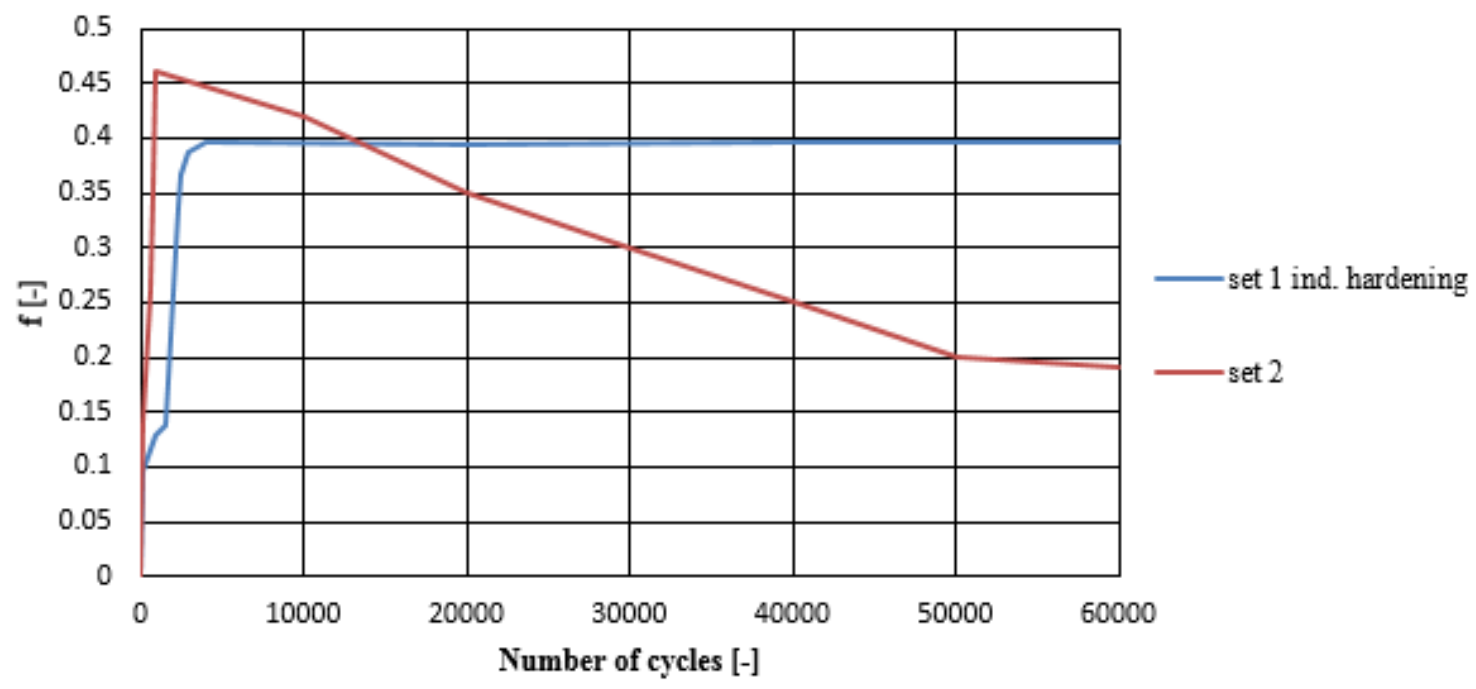

Fig. 4. Friction coefficient derived from recorded torque as function of number of cycles

\section{Wear model}

The applied wear model uses the shear band cracking mechanism [7] which is capable of predicting the wear process according to the accumulation of plastic shear strain beneath the contact surface. The wear process is considered by the mechanism as an independent simultaneous phenomenon. Removing process of material layers from the surface is a result of ductility exhaustion due to reaching the critical plastic shear strain in a particular depth beneath the contact surface. Cracks initiated in the close-to-surface layer follow the plastic lines according to the already-mentioned ductility exhaustion [8]. The ratcheting prediction in particular depths beneath the contact surface in case of the rolling/sliding two-dimensional contact was carried out based on the non-linear kinematic hardening rule introduced by Lemaitre and Chaboche which is described in detail in $[9,10]$ (see Table 2). In numerical simulations, the authors, unlike Mazzu [5], used two Voce rules which enabled them to control the entire hardening process more flexibly. The simulations also took into account the variability of the friction coefficient which played an important role in the beginning stage. In case of simulations for the set 1 , every ten cycles, an update of elastic stress field according to the actual value of friction coefficient was made. Beyond 5000 cycles, the value of friction coefficient became a constant $(f=0.39[-])$. In case of the set 2 , the values of friction coefficient were updated every 500 cycles during the entire simulation.

Material parameters for the following numerical simulations were obtained using a numerical approach developed by the authors themselves. Due to the nature of the problem, an optimization algorithm based on a particular gradient method could not be used. The reason was that the parameters were extremely varying and therefore, it was impossible to find the minimum of the multivariable function which would meet mathematical and physical interpretation.

The authors decided to use the optimization algorithm with incorporated random number generator. The optimization procedure started by defining the intervals for each parameter from which the random numbers had to be generated. The random number generator generally worked on the basis of generating numbers with uniform distribution pattern. One cycle contained three computations of worn layer under prescribed reference number of cycles. Afterwards, an error value was calculated in the following way 


$$
\operatorname{error}^{i}=\sum_{k=1}^{3}\left(\frac{\left|h_{W r e f k}-h_{W}{ }^{k}\right|}{h_{\text {Wref } k}}\right),
$$

where $h_{\text {Wref } k}$ was the reference value of the worn layer and $h_{W}{ }^{k}$ was the value of worn layer reached after specified number of cycles. Reference values of worn layers with corresponding number of cycles were obtained from realized experiments. The following flowchart shows individual steps of the calculation of plastic shear strain distribution over the depth beneath the contact surface.

Table 2. Chaboche-Lemaitre plasticity model.

\begin{tabular}{|c|c|}
\hline $\begin{array}{c}\text { Elastic domain definition } \\
\text { Back-stress variation law }\end{array}$ & $F=\left|\sqrt{3} \cdot \tau_{x z}-X_{x z}\right|-\left(R+\sigma_{L}\right) \leq 0$ \\
Isotropic term variation law & $d X_{x z}=C \cdot \frac{d \gamma_{x z}}{\sqrt{3}}-\gamma \cdot X_{x z} \cdot\left|\frac{d \gamma_{x z}}{\sqrt{3}}\right|$ \\
$\begin{array}{c}\text { Evaluation of back-stress variable } \\
\text { between two steps }\end{array}$ & $R=R_{\infty 1} \cdot\left[1-\exp \left(-b_{1} \cdot \frac{\gamma_{x z}}{\sqrt{3}}\right)\right]+R_{\infty 2} \cdot\left[1-\exp \left(-b_{2} \cdot \frac{\gamma_{x z}}{\sqrt{3}}\right)\right]$ \\
Plastic shear strain increment & $X_{x z}=v \cdot \frac{C}{\gamma}+\left(X_{x z}^{0}-v \cdot \frac{C}{\gamma}\right) \exp \left[-\frac{v \cdot \gamma}{\sqrt{3}} \cdot\left(\gamma_{x z}-\gamma_{x z}^{0}\right)\right]$ \\
& $\Delta \gamma_{x z}=-\frac{\sqrt{3}}{v \cdot \gamma} \cdot \ln \left[\frac{X_{x z}-v \cdot(C / \gamma)}{X_{x z}^{0}-v \cdot(C / \gamma)}\right]$ \\
\hline
\end{tabular}

Definition of parameters related to the contact conditions including range of inspected depths or number of simulated cycles

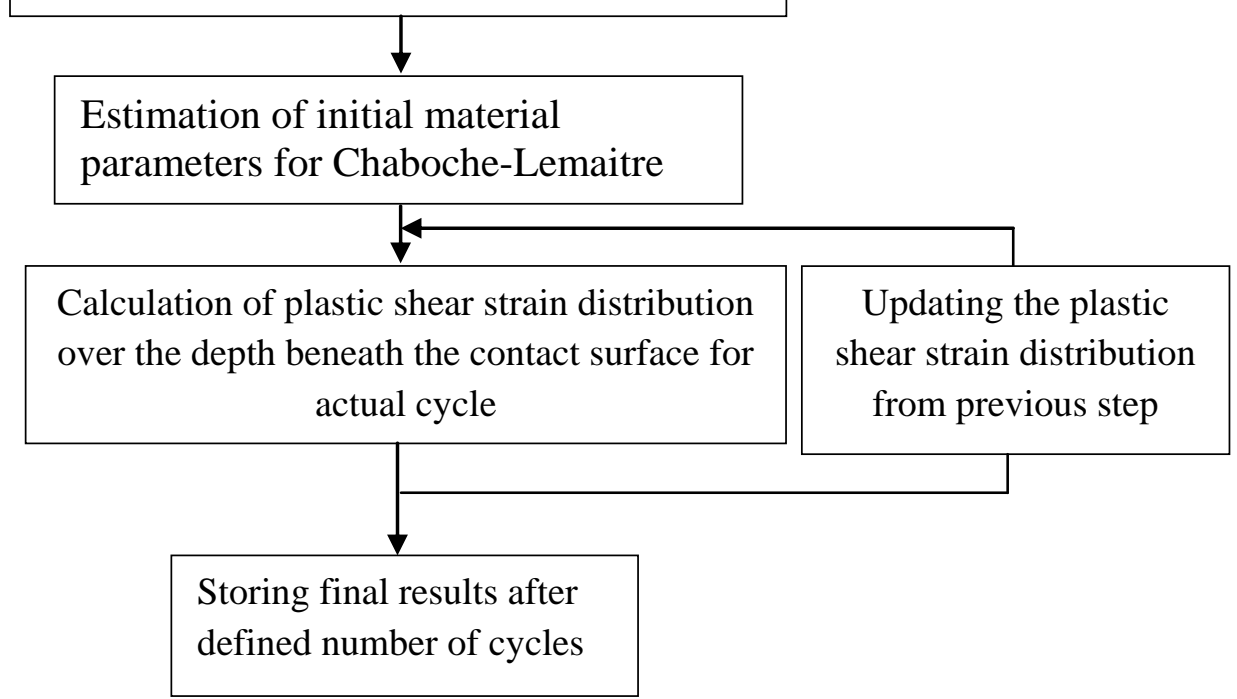

Fig. 5. Accumulated plastic shear strain profiles - Set 1, R7T (with induction hardening) 
The following tables summarize the obtained material parameters as well as additional parameters needed for numerical simulations.

Table 3. Parameters for numerical simulations - Set 1 R7T (with induction hardening)

\begin{tabular}{|c|c|c|c|c|c|}
\hline \multirow{3}{*}{\multicolumn{3}{|c|}{$\begin{array}{l}\text { Reference values of worn layer with } \\
\text { corresponding number of cycles obtained } \\
\text { from experiment }\end{array}$}} & \multirow{7}{*}{$\begin{array}{c}\text { Material } \\
\text { parameters }\end{array}$} & $C[\mathrm{MPa}]$ & 39437 \\
\hline & & & & $\gamma[-]$ & 0.4 \\
\hline & & & & $\sigma_{L}[\mathrm{MPa}]$ & 410 \\
\hline $\begin{array}{l}\text { Worn layer } \\
{[\mathrm{mm}]}\end{array}$ & \multicolumn{2}{|c|}{ Number of cycles [-] } & & $R_{\infty 1}[\mathrm{MPa}]$ & 54 \\
\hline 0.0006 & \multicolumn{2}{|c|}{10000} & & $b_{1}[-]$ & $2 \cdot 10^{-7}$ \\
\hline 0.011 & \multicolumn{2}{|c|}{20000} & & $R_{\infty 2}[\mathrm{MPa}]$ & 10 \\
\hline 0.049 & \multicolumn{2}{|c|}{60000} & & $b_{2}[-]$ & 0.001 \\
\hline \multicolumn{5}{|c|}{ Hertzian maximum contact pressure $p_{0}[\mathrm{MPa}]$} & 1200 \\
\hline \multicolumn{2}{|c|}{ Line contact parameters } & \multicolumn{3}{|c|}{ Hertzian contact half-width $a[\mathrm{~mm}]$} & 0.71 \\
\hline \multirow{3}{*}{\multicolumn{2}{|c|}{ Other parameters }} & \multicolumn{3}{|c|}{ Range of inspected depths $\mathrm{z}_{\min } / z_{\max }[\mathrm{mm}]$} & $\begin{array}{l}-0.0005 /- \\
0.2\end{array}$ \\
\hline & & \multicolumn{3}{|c|}{$\begin{array}{l}\text { Number of layers in the range of inspected } \\
\text { depths }\end{array}$} & 60 \\
\hline & & \multicolumn{3}{|c|}{ Critical plastic shear deformation $\gamma_{c r i t}[-]$} & 3.41 \\
\hline
\end{tabular}

Table 4. Parameters for numerical simulations - Set 2, R7T (without induction hardening)

\begin{tabular}{|c|c|c|c|c|c|}
\hline \multirow{3}{*}{\multicolumn{3}{|c|}{$\begin{array}{l}\text { Reference values of worn layer with } \\
\text { corresponding number of cycles obtained } \\
\text { from experiment }\end{array}$}} & \multirow{7}{*}{$\begin{array}{c}\text { Material } \\
\text { parameters }\end{array}$} & $C[\mathrm{MPa}]$ & 39437 \\
\hline & & & & $\gamma[-]$ & 0.8 \\
\hline & & & & $\sigma_{L}[\mathrm{MPa}]$ & 400 \\
\hline $\begin{array}{l}\text { Worn layer } \\
{[\mathrm{mm}]}\end{array}$ & \multicolumn{2}{|c|}{ Number of cycles [-] } & & $R_{\infty 1}[\mathrm{MPa}]$ & 54 \\
\hline 0.0127 & \multicolumn{2}{|c|}{10000} & & $b_{1}[-]$ & $2 \cdot 10^{-7}$ \\
\hline 0.0327 & \multicolumn{2}{|c|}{20000} & & $R_{\infty 2}[\mathrm{MPa}]$ & 20 \\
\hline 0.1127 & \multicolumn{2}{|c|}{60000} & & $b_{2}[-]$ & 0.001 \\
\hline \multicolumn{5}{|c|}{ Hertzian maximum contact pressure $p_{0}[\mathrm{MPa}]$} & 1200 \\
\hline \multicolumn{2}{|c|}{ Line contact parameters } & \multicolumn{3}{|c|}{ Hertzian contact half-width $a[\mathrm{~mm}]$} & 0.71 \\
\hline \multirow{3}{*}{\multicolumn{2}{|c|}{ Other parameters }} & \multicolumn{3}{|c|}{ Range of inspected depths $\mathbf{z}_{\min } / z_{\max }[\mathrm{mm}]$} & $\begin{array}{l}-0.0005 /- \\
0.25\end{array}$ \\
\hline & & \multicolumn{3}{|c|}{$\begin{array}{l}\text { Number of layers in the range of inspected } \\
\text { depths }\end{array}$} & 60 \\
\hline & & \multicolumn{3}{|c|}{ Critical plastic shear deformation $\gamma_{c r i t}[-]$} & 9.1 \\
\hline
\end{tabular}




\section{Results}

For each specimen set, three computations were made to obtain the plastic shear strain distribution over the depth beneath the contact surface as well as to estimate the thickness of a worn layer after 10000, 20000 and 60000 cycles. Figures 5 and 6 show the shapes of deformation profiles in case of a specimen with (Fig. 6) and without (Fig. 7) induction hardening. It can be seen that in case of the specimen with induction hardening, the profile tends to be stabilized even after 10000 cycles. This phenomenon is directly related to the presence of a material layer which underwent some type of additional heat treatment. On the other hand, the specimen without induction hardening exhibits evolution of the deformation profile shape throughout the entire testing. The results imply that the harder are the surface and subsurface material layers, the less number of cycles is needed for stabilization of the deformation profile.

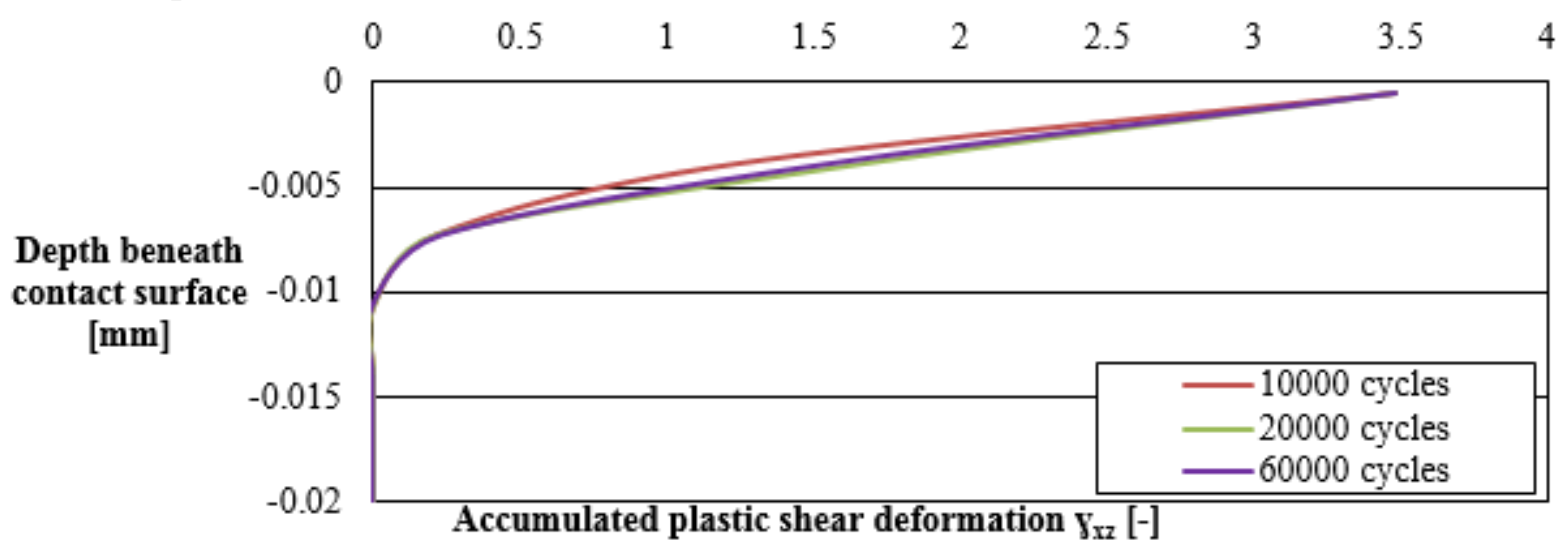

Fig. 6. Accumulated plastic shear strain profiles - Set 1, R7T (with induction hardening)

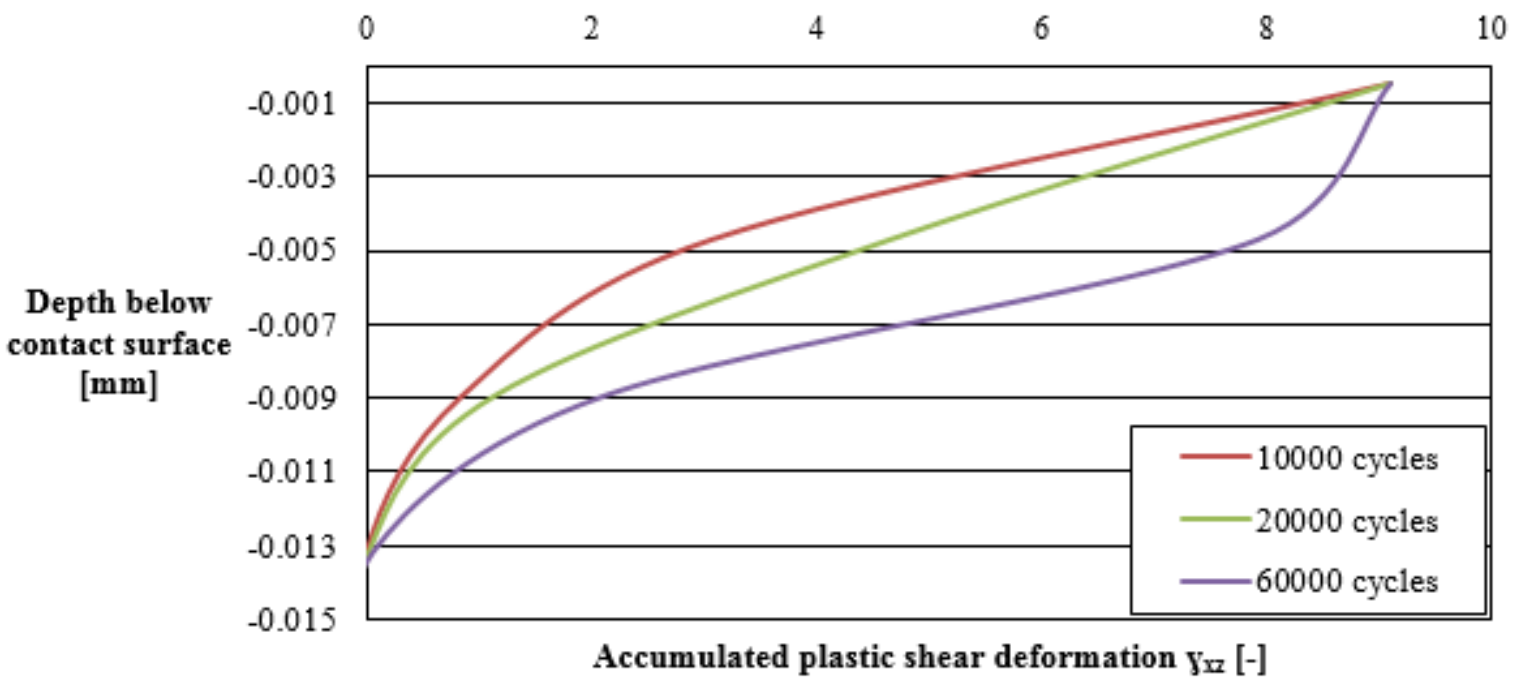

Fig. 7. Accumulated plastic shear strain profiles - Set 2, R7T (without induction hardening )

In case of the numerical simulations related to the specimen from the set 1 (with induction hardening), the thickness of the active layer is equal to 11 micrometers. On the other hand, the active layer in case of numerical simulations related to the specimen from the set 2 (without induction hardening) is equal to 14 micrometers. Figures 8 and 9 show the dependence of the loss of radius on the number of cycles. It can be clearly seen that in both cases, the presented wear model tends to predict the loss of diameter linearly compared to the experimental data. 


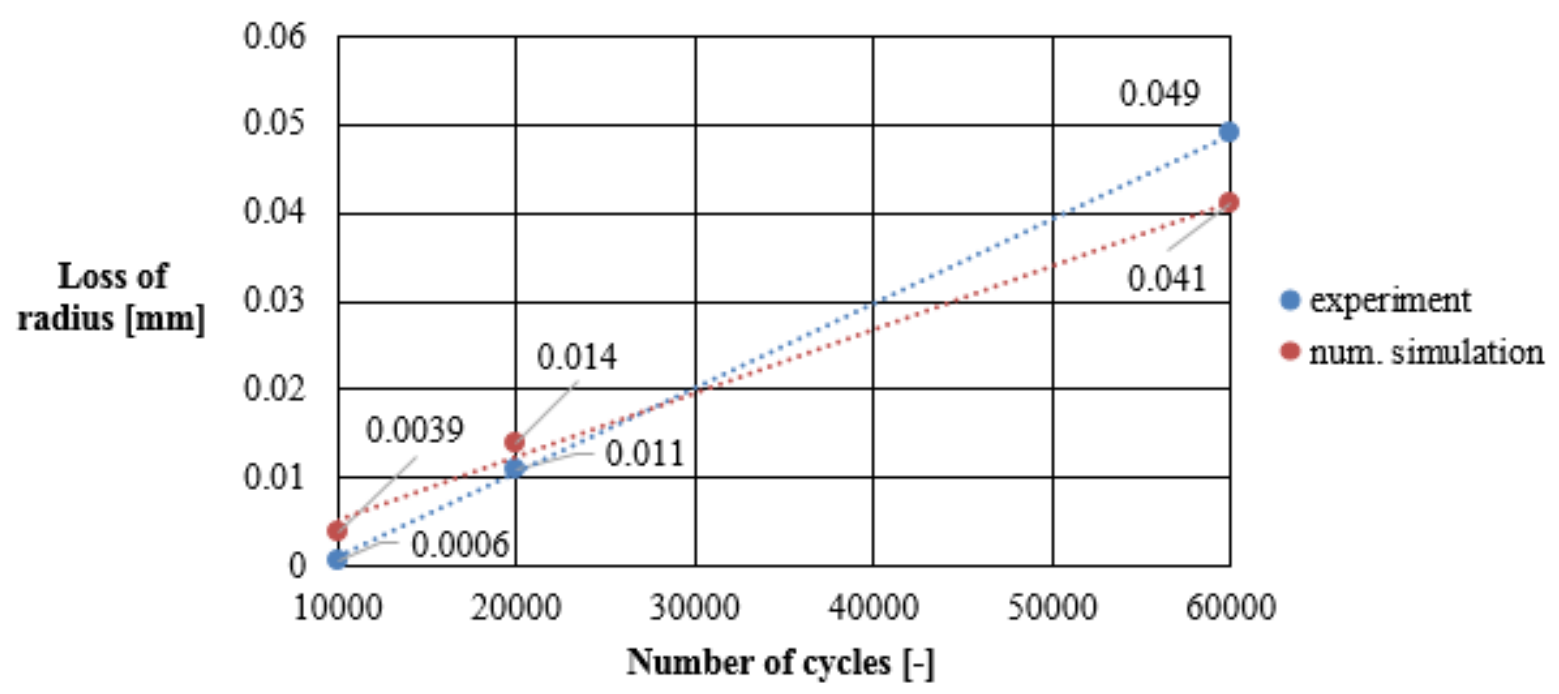

Fig. 8. Loss of radius as function of number of cycles - Set 1, R7T (with induction hardening)

In both cases, the conformity between the experiment and the numerical simulation is very good, considering that all calculations were made in very shallow depths beneath the contact surface.

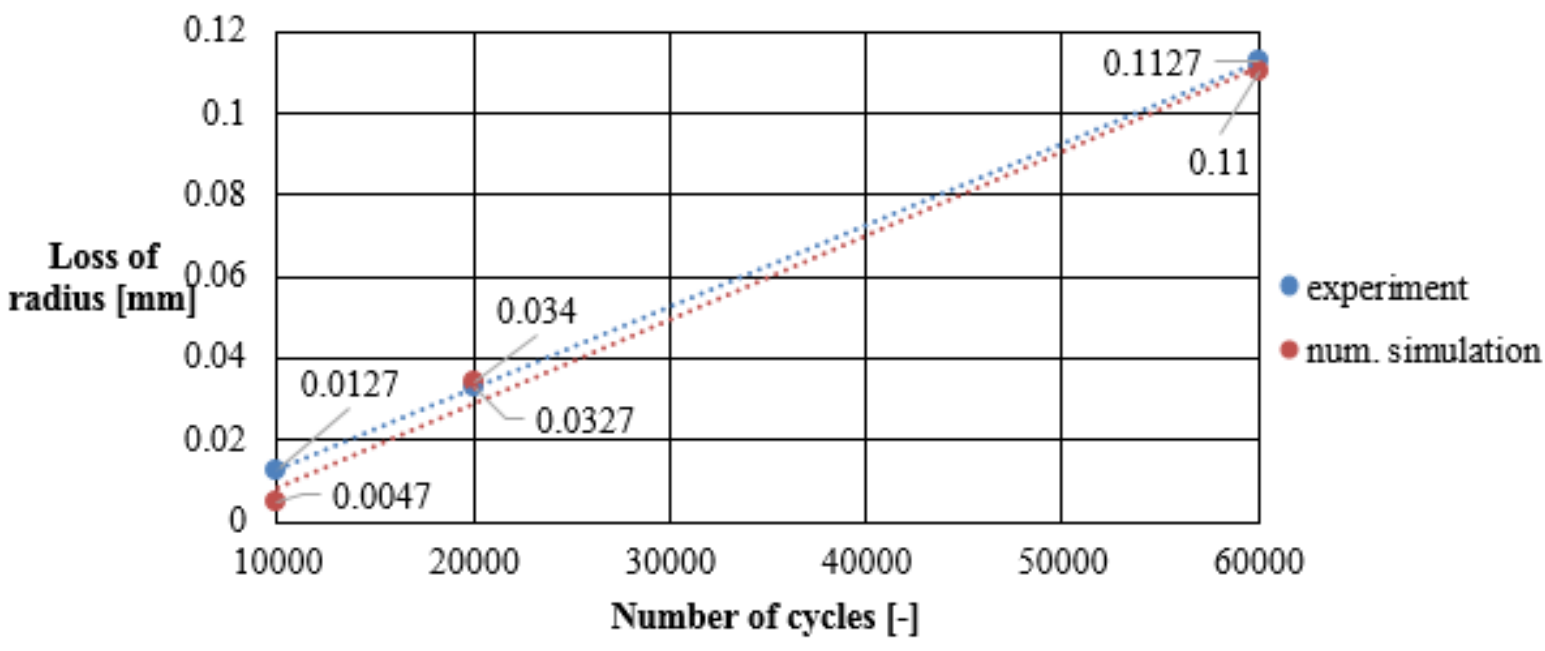

Fig. 9. Loss of radius as function of number of cycles - Set 2,

R7T (without induction hardening)

\section{Conclusion}

The main aim of the presented paper was to predict and subsequently compare the wear rates and deformation profiles of two sets of specimens which differed in additional heat treatment. In total, six numerical simulations were realized and the obtained results were compared with experiments. For this purpose, the authors used a wear model which is based on the shear band cracking mechanism [7] and ratcheting prediction applying the non-linear kinematic hardening rule introduced by Lemaitre and Chaboche $[9,10]$. The comparison of results obtained from numerical and experimental approaches showed very good agreement particularly as regards the loss of radius, taking into account that all computations were made in very shallow depths beneath the contact surface. The overall results show that the used wear model is applicable in various engineering applications which are related to the line rolling contact. 


\section{Acknowledgement}

This work has been elaborated in the framework of the project Opportunity for Young Researchers, reg. no. CZ.1.07/2.3.00/30.0016, supported by the Operational Programme Education for Competitiveness and co-financed by the European Social Fund and the state budget of the Czech Republic and in the framework of the IT4Innovations Centre of Excellence project, reg. no. CZ.1.05/1.1.00/02.0070, supported by Operational Programme Research and Development for Innovations and funded from the Structural Funds of the European Union; and also in the framework of project no. 15-18274S supported by the Grant Agency of the Czech Republic (GACR).

\section{References}

[1] MAZZU, A.: A simplified non-linear kinematic hardening model for ratcheting and wear assessment in rolling contact, Journal of Strain Analysis, 43, 2008, pp. 349-360

[2] TUNNA, J., SINCLAIR, J., PEREY, J.: A review of wheel wear and rolling contact fatigue, Development of a wheel wear and rolling contact fatigue model-Research programme, UK Proprietary 05-009, 2006

[3] TYFOUR, W.R., BEYNON, J.H., KAPOOR, A.: Deterioration of rolling contact fatigue life of pearlitic rail due to dry-wet rolling-sliding line contact, Wear, 197, 1996, pp. 255-265

[4] KAPOOR, A., FRANKLIN, F.J., KAPOOR, A.: Tribological layers and the wear of ductile materials, Wear, 245, 2000, pp. 204-215

[5] MAZZU, A.: Surface plastic strain in contact problems: prediction by a simplified nonlinear kinematic hardening model, Journal of Strain Analysis, 44, 3, 2009, pp. 187-199

[6] HALAMA, R., FAJKOŠ, R., MATUŠEK, P., BÁBKOVÁ, P. FOJTÍK, F. VÁCLAVEK, L.: Contact defects initiation in railroad wheels - Experience, experiments and modelling, Wear, 271, 2011, pp. 174-185

[7] DONZElla, G., FACCOLI, M., MAZZU, A., PETROGAlli C., ROBERTI, R.: Progressive damage assessment in the near-surface layer of railway wheel-rail couple under cyclic contact, Wear, 271, 2011, pp. 408-416

[8] SU, X., CLAYTON, P., Surface initiated rolling contact fatigue of pearlitic and low carbon bainitic steels, Wear, 197, 1996, pp. 137-144

[9] LEMAITRE, J., CHABOCHE, J., L.: Mechanics of solid materials, Cambridge University Press, Cambridge, 1994

[10] JANČO, R.: Solution of thermo-elastic-plastic problems with consistent integration of constitutive equations. In: Strojnicky časopis - Journal of Mechanical engineering, ISSN 0039-2472, Vol. 53, No. 4, 2002, pp. 197-214 
